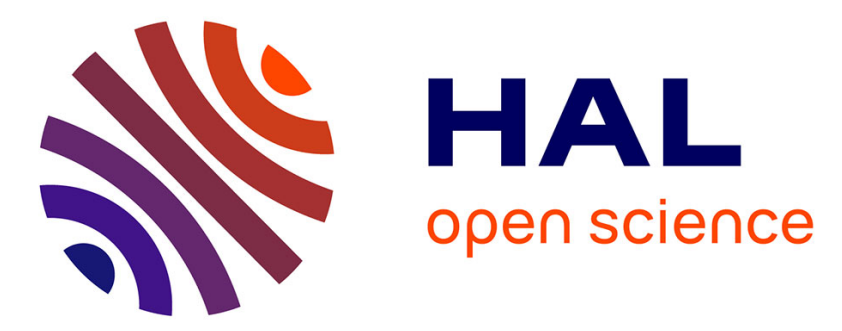

\title{
Acetonitrile allows indirect replacement of non-deuterated lipid detergents by deuterated lipid detergents for the NMR study of detergent-soluble proteins
}

Xiao Wang, Xiaowei Chen, Serge Bouaziz, Sylvie Nonin-Lecomte

\section{To cite this version:}

Xiao Wang, Xiaowei Chen, Serge Bouaziz, Sylvie Nonin-Lecomte. Acetonitrile allows indirect replacement of non-deuterated lipid detergents by deuterated lipid detergents for the NMR study of detergent-soluble proteins. Protein Science, 2021, 10.1002/pro.4174 . hal-03331437

\section{HAL Id: hal-03331437 \\ https://hal.science/hal-03331437}

Submitted on 6 Sep 2021

HAL is a multi-disciplinary open access archive for the deposit and dissemination of scientific research documents, whether they are published or not. The documents may come from teaching and research institutions in France or abroad, or from public or private research centers.
L'archive ouverte pluridisciplinaire HAL, est destinée au dépôt et à la diffusion de documents scientifiques de niveau recherche, publiés ou non, émanant des établissements d'enseignement et de recherche français ou étrangers, des laboratoires publics ou privés. 
Acetonitrile allows indirect replacement of non-deuterated lipid detergents by deuterated lipid detergents for the NMR study of detergent-soluble proteins

Xiao Wang, Xiaowei Chen, Sylvie Nonin-Lecomte, Serge Bouaziz*

CiTCoM, CNRS, UMR 8038, Université de Paris, 4 Avenue de l'Observatoire, Paris, 75270, France.

*Corresponding author: serge.bouaziz@parisdescartes.fr 


\begin{abstract}
Detergent-soluble proteins (DSPs) are commonly dissolved in lipid buffers for NMR experiments, but the huge lipid proton signal prevents recording of high-quality spectra. The use of costly deuterated lipids is thus required to replace non-deuterated ones. With conventional methods, detergents like dodecylphosphocholine (DPC) cannot be fully exchanged due to their high binding affinity to hydrophobic proteins. We propose an original and simple protocol which combines the use of acetonitrile, dialysis and lyophilization to disrupt the binding of lipids to the protein and allow their indirect replacement by their deuterated equivalents, while maintaining the native structure of the protein. Moreover, by this protocol, the detergent-to-protein molar ratio can be controlled as it challenges the protein structure. This protocol was applied to solubilize the Vpx protein that was followed upon addition of DPC- $d_{38}$ by ${ }^{1} \mathrm{H}-{ }^{15} \mathrm{~N}$ SOFAST-HMQC spectra and the best detergent-to-DSPs molar ratio was obtained for structural studies.
\end{abstract}

\title{
KEYWORDS
}

NMR, detergent-soluble proteins, 3D structure, acetonitrile, DPC-to-protein molar ratio
Abbreviations: CD, circular dichroism; DPC, dodecylphosphocholine; DPC- $d_{38}$, deuterated DPC; DSP, detergent-soluble protein; HMQC, heteronuclear multiple quantum coherence; NMR, nuclear magnetic resonance; SDS, sodium dodecyl sulphate; TFA, trifluoroacetic acid; TFE, trifluoroethanol; TMD, transmembrane domain. 


\section{INTRODUCTION}

The hydrophobicity of some proteins challenges their purification in liquid phase as they are not soluble in aqueous buffers. Denaturation agents such as urea and guanidine hydrochloride can be used for solubilization, ${ }^{1-5}$ but at the expense of the protein native structure. A renaturation step is therefore required, but the process of renaturation remains poorly controlled and the ultimately obtained structure may be different from the native conformation. Lipid detergents such as dodecylphosphocholine (DPC) and sodium dodecyl sulphate (SDS) are alternatively employed to successfully solubilize these proteins called detergent-soluble proteins (DSPs) of which the human amylin and the SARS-CoV-2 spike proteins. ${ }^{6-10}$ Unfortunately, the large number of protons of these detergents prevents the recording of NMR spectra with acceptable signal-to-noise ratio, thus compromising subsequent analyses like structure determination and interaction studies with protein or ligand partners for the identification of new drugs and targets. Detergents, often lipids, should be replaced by their deuterated equivalents. The price of deuterated detergents is high and prevents their use from the first to the last steps of purification. Various detergent removal methods were described such as gel filtration, dialysis, precipitation and ion-exchange chromatography, ${ }^{11-14}$ but the effectiveness of their removal is still uncertain since some detergents such as DPC and SDS can bind to DSPs so tightly that they cannot be removed. A solution might be to perform the full extraction and purification procedures in deuterated detergents, but the high cost of such a protocol is also a deterrent. Therefore, a new efficient and economical solution is required for the removal and exchange of lipid detergents. 
Literature shows that some DSPs were well solubilized and folded in organic solvents such as acetonitrile or trifluoroethanol (TFE), albeit not under near physiological conditions. For example, the synthetic HIV-1 Vpr adopts a three $\alpha$-helical structure in the presence of acetonitrile, ${ }^{15}$ which is almost identical to the structure determined later by X-ray crystallography. ${ }^{16}$ Similarly, the structure of HCV p7 is mainly $\alpha$-helical, whether in detergents or in organic solvent/water mixtures as shown by circular dichroism (CD) analyses. ${ }^{17}$ Subsequently, the proteins HIV-1 Vpr and HCV p7 were reported to be well structured in detergent micelles. ${ }^{18,19}$ Thus, these proteins are well folded in organic solvents and detergents micelles. Lipids are soluble and can be purified in organic solvents. ${ }^{20-22}$

Structure, multimerization and aggregation of DSPs strongly depend on the detergent-toDSP molar ratio. For example, the oligomerization of $\mathrm{HCV} \mathrm{p7} \mathrm{protein} \mathrm{was} \mathrm{reported} \mathrm{to} \mathrm{be} \mathrm{highly}$ sensitive to the detergent-to-protein molar ratio. ${ }^{23}$ It is important for structural and biophysical studies to retain the native structure of the protein and thus to determine the optimal lipid-toDSP ratio to ensure native and monodisperse structuration of the protein. A slight change in the detergent-to-protein ratio can induce chemical shift perturbations in NMR spectra, ${ }^{24}$ which hampers further analyses and identification of protein-protein or protein-ligand interactions by the method of chemical shifts perturbations induced upon partner binding.

In this study, we present a new protocol which ensures total removal of the lipids while retaining the structural properties of the DSP based on our assumption that the detergent molecules coating the protein can be easily and totally replaced by organic solvent molecules during dialysis. In a second step, the deuterated detergent can be added to the buffer, and a near membrane condition can be obtained by eliminating the organic solvent by lyophilization. Thus, 
the aim of this work was to replace the non-deuterated DPC by deuterated DPC (DPC- $\left.d_{38}\right)$. Then to determine the best detergent-to-protein ratio, a series of high resolution ${ }^{1} \mathrm{H}_{-}{ }^{15} \mathrm{~N}$ SOFAST-HMQC ${ }^{25}$ spectra were recorded in different detergent-to-DSP molar ratios. Finally, a 300:1 molar ratio was defined and obtained when the molar ratio of 400:1 only induced very slight change compared with the equivalent at 300:1. In conclusion, we performed an indirect replacement of detergents by their deuterated equivalents and determined best detergent-toDSPs molar ratio.

\section{RESULTS}

\section{Acetonitrile disrupts the binding of detergent molecules}

As a prototype, we used the highly hydrophobic protein Vpx, a DSP from macaque simian immunodeficiency virus (SIVmac). Vpx extraction after bacteria cells lysis and purification were both conducted in protonated DPC buffer. To eliminate DPC, acetonitrile was used to efficiently disrupt the binding of DPC to Vpx (Figure 1). Proton NMR spectra confirm that DPC can be removed completely during dialysis steps against acetonitrile (Figure 2). Organic solvents are thus effective to disrupt the binding of the coating detergent molecules.

\section{Acetonitrile retains the structural properties of the DSP}

Maintaining the native structure of the protein is very important for the structural studies. The elimination of detergents leads to the precipitation or unfold conformation of DSPs. Some DSPs are well-folded in both detergent and organic solvent. Here, to confirm the structural 
character of Vpx in the context of acetonitrile, a ${ }^{1} \mathrm{H}_{-}{ }^{15} \mathrm{~N}$ SOFAST-HMQC spectra was recorded (Figure 3). Our NMR spectra shows that acetonitrile buffer retains the structural conformation of $\mathrm{Vpx}$ and prevents its aggregation by offering adequate hydrophobic conditions.

\section{DPC- $d_{38}$ prevents aggregation during lyophilization}

After the elimination of DPC micelles, we directly lyophilized the sample and found that the lyophilized sample without DPC- $d_{38}$ was aggregated and somehow attached to the wall of the eppendorf (Figure 4A). Then, we dissolved the lyophilized sample with DPC- $d_{38}$ in acetate buffer, but only a small part of them was solubilized. We propose that DSPs without DPC may aggregate during the freeze-drying process. Thus, prior to lyophilization, the sample was supplied with 100 equivalents of DPC- $d_{38}$ to avoid protein aggregation upon acetonitrile lyophilization. We found that the lyophilized sample in the presence of DPC- $d_{38}$ was porous and fibrous (Figure 4B) indicating that DPC- $d_{38}$ can act as a freeze-drying protective agent.

\section{The best detergent-to-DSP molar ratio is determined by NMR}

DSPs usually have different spectrum at different detergent-to-DSP molar ratios suggesting that the structure of DSPs evolves at different detergent-to-DSP molar ratios. Thus, structure, multimerization and aggregation of DSPs strongly depend on the detergent-to-DSP molar ratio. To obtain the best detergent-to-DSP molar ratio, the precise DPC- $d_{38}$-to-Vpx ratio for the structural and interaction studies is determined by NMR, using only a small amount of labeled protein ( $\sim 60 \mathrm{nmol}$ per tube). Different detergent-to-Vpx molar ratios, starting with 100:1, were assayed by ${ }^{1} \mathrm{H}-{ }^{15} \mathrm{~N}$ SOFAST-HMQC spectra until no significant chemical shift 
perturbations of the protein resonances occurred (Figure 5A-E). We found only very slight changes between molar ratios of 300:1 and 400:1 (Figure 5F). Therefore, a 300:1 DPC- $d_{38}$-toVpx ratio was considered as suitable for structural analysis by NMR. In addition, the spectrum at a 300: 1 DPC- $d_{38}$-to-Vpx molar ratio is identical to the spectrum at the same DPC-to-Vpx ratio (Figure S1). Two residues A96 and A112 located at the C-terminus of Vpx have slight change in chemical shift probably resulting from indirect effects of the flexibility of the Cterminus.

\section{DISCUSSION}

The purification of DSPs is usually performed using denaturing agents such as urea or guanidinium salts, in which DSPs may have different conformations before and after renaturation. Maintaining the native structure of the protein is very important for structural studies and the use of detergents can avoid the denaturation or aggregation of DSPs during extraction and purification. Unfortunately, the large number of protons contained in these detergents complicates NMR spectra analysis and compromises the downstream structure determination of the protein and its interaction with ligands for the identification of new drugs. Detergent removal efficiency is still a challenge since various methods cannot remove efficiently detergent bound to the protein. The extremely high price of deuterated detergents must also be considered.

Organic solvents are widely used to study the protein properties in biochemical physics, biotechnology, and biomedicine. The advantages of the organic solvents are that they overcome 
unwanted water-dependent side reactions and provide a hydrophobic environment in which hydrophobic force is involved in maintain 3D structure of proteins. ${ }^{26-28}$ Among several organic solvents, acetonitrile and TFE are most widely utilized due to their low viscosity and high hydrophobicity. ${ }^{29}$ In our protocol, acetonitrile allows efficient exchange of non-deuterated lipid detergents by deuterated ones, while retaining the 3D structure of the protein. It is possible, then, to record high-resolution NMR spectra, free of interfering proton signals from detergent, required for NMR studies of proteins isolated or in interaction with their partners. Importantly, Vpx in 30\% acetonitrile solution still maintains its 3D structure during the substitution between DPC and DPC- $d_{38}$. Similar with the structure of Vpx in acetonitrile, our previous study showed that HIV-1 Vpr is organized around three well defined $\alpha$-helices in $30 \%$ acetonitrile solution. ${ }^{30}$ Other proteins in acetonitrile aqueous such as subtilisin Carlsburg and human insulin are well characterized in their 3D structure. ${ }^{31-33}$ In addition, solution NMR structure of protein-G B1 domain display native-like $\beta$-hairpin tertiary structure in $30 \%$ TFE solution. ${ }^{34}$ TFE and acetonitrile are polar solvents that can easily repel water from the protein surface. Consequently, side chains of polar residues in proteins become more rigid, and favor interactions with other residues by intramolecular hydrogen bonds, which explains why certain organic solvents maintain 3D structures and secondary structural elements. However, the 3D structure of proteins could be perturbed in organic solvents including trifluoroacetic acid (TFA) and acetonitrile. Acetonitrile and TFE have strong electronegativity so that they can form strong hydrogen bonds with various hydrogen donors. ${ }^{35}$ Thus, acetonitrile and TFE perturb 3D structure of proteins by disrupting intramolecular hydrogen bonds. In addition, Gekko et al. reported that the stability of the $3 \mathrm{D}$ structure of protein depends on the organic solvent 
concentration using hen-egg lysozyme as a prototype. ${ }^{36}$ Their results suggest that the perturbation of 3D structure does not occur at low concentrations of acetonitrile (below $40 \%$ acetonitrile). However, the hydrophobic bonding capacity for nonpolar sidechains is weakened with the addition of acetonitrile, consequently, leading to destabilization of the 3D structure of proteins..$^{36}$ In our study, $30 \%$ acetonitrile, a low concentration used, is favorable for maintaining native state of $\mathrm{Vpx}$. Thus, a preferential concentration of acetonitrile or other organic solvents such as TFE and methanol needs to be investigated to ensure the degree of solubilization and folding of DSPs when applying our protocol.

On the other hand, this protocol deserves to be tested even if the 3D structure of the protein is lost in the presence of organic solvent. Indeed, in the case where the protein would be able to fold after elimination of the organic solvent by lyophilization, this would make it possible to widen the applicability to other classes of proteins solubilized by a detergent.

Non-deuterated DPC was used to solubilize Vpx and was removed by dialysis against acetonitrile. Then, DPC- $d_{38}$ was supplied, the sample lyophilized, and acetate buffer added for NMR studies. However, all DSPs are not always well-folded in the presence of DPC micelles, although DPC is the most widely used detergent in solution NMR, and it is possible to adapt our protocol to other detergents. Similar with DPC, SDS is a lipid detergent as well. DPC and SDS, not only create a hydrophobic environment through their nonpolar tails preventing protein self-aggregation, but they also provide a suitable polyelectrolytic environment through polar heads allowing protein-protein interactions. ${ }^{28}$ Furthermore, SDS has the same long hydrophobic carbon chain $\mathrm{CH}_{3}\left(\mathrm{CH}_{2}\right)_{11}$ as DPC suggesting that SDS binds to DSPs in the same 
way as DPC. Thus, our protocol could be applied to the substitution of SDS. In comparison with the monolayer of DPC or SDS, some other lipid detergents such as 1,2- diheptanoyl-snglycero-3-phosphocholine (DHPC) and 1,2-dioleoyl-sn-glycero-3-phosphocholine (DOPC) have bilayer properties. Thus, whether acetonitrile or other organic solvents can be used for the substitution has to be checked.

Vpx is a small size hydrophobic protein, which remains folded under a variety of experimental conditions in this study. Most membrane proteins have one or several transmembrane domains (TMDs), ${ }^{37-39}$ and their TMDs are usually composed by small size $\alpha-$ helical domains. Furthermore, many TMDs are well organized with $\alpha$-helices in detergents. For example, $\alpha$-helical structures of TMDs from lysosome-associated membrane protein type 2a, influenza A virus M2, phospholamban, and human nicastrin are well organized in DPC micelles. ${ }^{40-43}$ Currently, DPC has been used to obtain $40 \%$ of the membrane protein structures determined by solution NMR, making it the most frequently used detergent. ${ }^{45}$ Interestingly, organic solvents, including TFA and acetonitrile, can promote or maintain secondary structural elements and mostly work for helical proteins suggesting that many transmembrane domains possibly fold well in certain organic solvents and in detergents. For example, the TMDs of the cannabinoid receptor subtype 2, a member of the well-characterized G-protein coupled receptor superfamily, folds well in acetonitrile and in DPC micelles. ${ }^{44}$ If membrane proteins fold well in organic solvents, our protocol could be widely applied for DSPs, membrane proteins or even protein with more complex topology. 
In this study, acetonitrile was used to break down the hydrophobic forces between protein and detergent and was then removed by dialysis. Subsequently, a few tests were made on samples adding very small amount of deuterated detergent prior to acetonitrile removal by lyophilization. Our protocol allows maintaining the original state of the native protein and compared to $\mathrm{TMDs}^{1}$ protocols, it avoids the process of protein denaturation and renaturation. Our protocol is thus expected to have a broad impact on the research community studying hydrophobic proteins in solution.

\section{MATERIALS AND METHODS}

\section{Elimination of detergents}

The ${ }^{13} \mathrm{C},{ }^{15} \mathrm{~N}$-labeled Vpx was produced in E. coli, extracted, and purified by liquid chromatography in acetate buffer $\mathrm{A}(10 \mathrm{mM}$ sodium acetate, $50 \mathrm{mM} \mathrm{NaCl}$ and $5 \mathrm{mM} \quad \beta$ mercaptoethanol buffer at $\mathrm{pH} 4.0$ ) supplemented with $6 \mathrm{mM}$ protonated DPC. The purified protein was concentrated on a $3 \mathrm{kDa}$ Amicon Ultra-15 and dialyzed at room temperature against $30 \%$ acetonitrile $/ 70 \% \mathrm{H}_{2} \mathrm{O}$ at $\mathrm{pH} 2.5$ to remove salts and DPC. The quantity of protein was determined from the $\mathrm{OD}_{280}$ absorbance value using the acetonitrile dialysis buffer as blank control. All NMR spectra were recorded in $3 \mathrm{~mm}$ tubes at $323 \mathrm{~K}$ on a Bruker Avance III 600 MHz spectrometer equipped with triple resonance cryoprobe and Z-gradients. The efficiency of DPC removal was determined by proton 1D NMR spectra. 


\section{Acetonitrile removal by lyophilization}

Prior to lyophilization, DPC- $d_{38}$ was added to the sample in Eppendorf that was frozen in liquid nitrogen. The frozen sample was lyophilized in a freeze dryer (Cryotec, Lyophilisateur Crios model) and acetonitrile was gradually removed. After lyophilization, acetate buffer was used to re-dissolve the freeze-dry sample. As a control, the sample without DPC- $d_{38}$ was directly lyophilized.

\section{Quantification of the best ratio between detergents and DSPs}

To determine the best detergent-to-DSP ratio by NMR, a small portion of labeled Vpx protein was aliquoted into 5 Eppendorf (i.e. $\sim 60$ nmol per sample) and DPC- $d_{38}$ was individually added at molar ratios ranging from 100:1 to 500:1 prior to lyophilization. After lyophilization, the five samples were resuspended in $200 \mu \mathrm{L}$ of acetate buffer $\mathrm{A} .{ }^{1} \mathrm{H}-{ }^{15} \mathrm{~N}$ SOFAST-HMQC ${ }^{25}$ spectra were recorded and compared. The best ratio (300:1) is obtained when the addition of DPC- $d_{38}$ no longer induces chemical shifts perturbations on the SOFASTHMQC spectrum.

\section{ORCID}

Serge Bouaziz https://orcid.org/0000-0001-7792-8307

Xiao Wang https://orcid.org/0000-0001-5811-8712

Xiaowei Chen https://orcid.org/0000-0001-8894-9429

Sylvie Nonin-Lecomte https://orcid.org/ 0000-0001-5155-8088 


\section{ACKNOWLEDGMENTS}

We gratefully thank Dr. Andrea Cimarelli, Centre International de Recherche en Infectiologie (CIRI), Université de Lyon 1, for kindly providing the plasmid pET11d -SIVmac Vpx. We are grateful to Dr. Valéry Larue for his help in setting up the NMR experiments. Xiao Wang was granted by China Scholarship Council ( $\left.\mathrm{n}^{\circ} 201709110124\right)$. This work was supported by the French Centre National de la Recherche Scientifique (CNRS) and the University of Paris.

\section{REFERENCES}

1. Fu Q, Piai A, Chen W, Xia K, Chou JJ (2019) Structure determination protocol for transmembrane domain oligomers. Nat Protoc 14:2483-2520.

2. Rossky PJ (2008) Protein denaturation by urea: Slash and bond. Proc Natl Acad Sci USA 105:16825-16826.

3. Maxwell KL, Bona D, Liu C, Arrowsmith CH, Edwards AM (2003) Refolding out of guanidine hydrochloride is an effective approach for high-throughput structural studies of small proteins. Protein Sci 12:2073-2080.

4. Hagihara Y, Aimoto S, Fink AL, Goto Y (1993) Guanidine hydrochloride-induced folding of proteins. J Mol Biol 231:180-184.

5. Huang SK, Shin K, Sarker M, Rainey JK (2017) Apela exhibits isoform- and headgroupdependent modulation of micelle binding, peptide conformation and dynamics. Biochim Biophys Acta Biomembr 1859:767-778.

6. Rabilloud T, Luche S, Santoni V, Chevallet M (2007) Detergents and chaotropes for protein solubilization before two-dimensional electrophoresis. Methods Mol Biol 355:111-119.

7. Matar-Merheb R, Rhimi M, Leydier A, Huché F, Galián C, Desuzinges-Mandon E, Ficheux D, Flot D, Aghajari N, Kahn R et al (2011) Structuring detergents for extracting and stabilizing functional membrane proteins. PLOS ONE 6:e18036.

8. Linke D (2009) Detergents: an overview. Methods Enzymol 463:603-617.

9. Zhang J, Cai Y, Xiao T, Lu J, Peng H, Sterling SM, Walsh RM, Rits-Volloch S, Sliz P, Chen B (2020) Structural impact on SARS-CoV-2 spike protein by D614G substitution. bioRxiv:2020.10.13.337980. 
10. Patil SM, Xu S, Sheftic SR, Alexandrescu AT (2009) Dynamic alpha-helix structure of micelle-bound human amylin. J Biol Chem 284:11982-11991.

11. Lin S-H, Guidotti G (2009) Purification of membrane proteins. Methods Enzymol 463:619629.

12. Antharavally BS, Mallia KA, Rosenblatt MM, Salunkhe AM, Rogers JC, Haney P, Haghdoost N (2011) Efficient removal of detergents from proteins and peptides in a spin column format. Anal Biochem 416:39-44.

13. Rigaud J-L, Levy D, Mosser G, Lambert O (1998) Detergent removal by non-polar polystyrene beads. Eur Biophys J 27:305-319.

14. Ohlendieck K (1996) Removal of detergent from protein fractions. Methods Mol Biol 59:305-312.

15. Morellet N, Bouaziz S, Petitjean P, Roques BP (2003) NMR structure of the HIV-1 regulatory protein VPR. J Mol Biol 327:215-227.

16. Wu Y, Zhou X, Barnes CO, DeLucia M, Cohen AE, Gronenborn AM, Ahn J, Calero G (2016) The DDB1-DCAF1-Vpr-UNG2 crystal structure reveals how HIV-1 Vpr steers human UNG2 toward destruction. Nat Struct Mol Biol 23:933-940.

17. Montserret R, Saint N, Vanbelle C, Salvay AG, Simorre J-P, Ebel C, Sapay N, Renisio JG, Böckmann A, Steinmann E et al. (2010) NMR structure and ion channel activity of the p7 protein from Hepatitis C virus. J Biol Chem 285:31446-31461.

18. Salgado GF, Marquant R, Vogel A, Alves ID, Feller SE, Morellet N, Bouaziz S (2009) Structural studies of HIV-1 Gag p6ct and its interaction with Vpr determined by solution nuclear magnetic resonance. Biochemistry 48:2355-2367.

19. Oestringer BP, Bolivar JH, Claridge JK, Almanea L, Chipot C, Dehez F, Holzmann N, Schnell JR, Zitzmann N (2019) Hepatitis C virus sequence divergence preserves $\mathrm{p} 7$ viroporin structural and dynamic features. Sci Rep 9:8383.

20. Ranjith Kumar R, Hanumantha Rao P, Arumugam M (2015) Lipid extraction methods from microalgae: A comprehensive review. Front Energy Res 2:61.

21. Roby MHH Synthesis and Characterization of Phenolic Lipids. IntechOpen; 2017. Available from: https://www.intechopen.com/books/phenolic-compounds-natural-sourcesimportance-and-applications/synthesis-and-characterization-of-phenolic-lipids

22. Downey WK, Keogh MK, Murphy RF (1968) Lipid separation on sephadex LH-20. Biochem J 110:13P-14P.

23. Chen W, OuYang B, Chou JJ (2019) Critical effect of the detergent:protein ratio on the formation of the Hepatitis C virus p7 channel. Biochemistry 58:3834-3837. 
24. Williamson MP (2013) Using chemical shift perturbation to characterise ligand binding. Prog Nucl Magn Reson Spectrosc 73:1-16.

25. Favier A, Brutscher B (2019) NMRlib: user-friendly pulse sequence tools for Bruker NMR spectrometers. J Biomol NMR 73:199-211.

26. Fetzner S, Lingens F (1994) Bacterial dehalogenases: biochemistry, genetics, and biotechnological applications. Microbiol Rev 58:641-685.

27. Torres S, Castro GR (2004) Non-aqueous biocatalysis in homogeneous solvent systems. Food Technol Biotechnol 42:271-277.

28. Maurel P, Douzou P, Waldmann J, Yonetani T (1978) Enzyme behaviour and molecular environment. The effects of ionic strength, detergents, linear polyanions and phospholipids on the $\mathrm{pH}$ profile of soluble cytochrome oxidase. Biochim Biophys Acta 525:314-324.

29. Rubinstein M (1979) Preparative high-performance liquid partition chromatography of proteins. Anal Biochem 98:1-7.

30. Schwefel D, Groom HCT, Boucherit VC, Christodoulou E, Walker PA, Stoye JP, Bishop KN, Taylor IA (2014) Structural basis of lentiviral subversion of a cellular protein degradation pathway. Nature 505:234-238.

31. Fitzpatrick PA, Ringe D, Klibanov AM (1994) X-ray crystal structure of cross-linked subtilisin Carlsberg in water vs. acetonitrile. Biochem Biophys Res Commun 198:675-681.

32. Fedorov AA, Joseph-McCarthy D, Fedorov E, Sirakova D, Graf I, Almo SC (1996) Ionic interactions in crystalline bovine pancreatic ribonuclease A. Biochemistry 35:15962-15979.

33. Bocian W, Sitkowski J, Bednarek E, Tarnowska A, Kawecki R, Kozerski L (2008) Structure of human insulin monomer in water/acetonitrile solution. J Biomol NMR 40:55-64.

34. Blanco FJ, Jiménez MA, Pineda A, Rico M, Santoro J, Nieto JL (1994) NMR solution structure of the isolated $\mathrm{N}$-terminal fragment of protein-G B1 domain. Evidence of trifluoroethanol induced native-like beta-hairpin formation. Biochemistry 33:6004-6014.

35. Cringus D, Yeremenko S, Pshenichnikov MS, Wiersma DA (2004) Hydrogen bonding and vibrational energy relaxation in water-acetonitrile mixtures. J Phys Chem B 108:10376-10387.

36. Gekko K, Ohmae E, Kameyama K, Takagi T (1998) Acetonitrile-protein interactions: amino acid solubility and preferential solvation. Biochim Biophys Acta Protein Struct Mol Enzymol 1387:195-205.

37. Sharpe HJ, Stevens TJ, Munro S (2010) A comprehensive comparison of transmembrane domains reveals organelle-specific properties. Cell 142:158-169.

38. White SH, Wimley WC (1999) Membrane protein folding and stability: Physical principles. Annu Rev Biophys Biomol Struct 28:319-365. 
39. Killian JA, von Heijne G (2000) How proteins adapt to a membrane-water interface. Trends Biochem Sci 25:429-434.

40. Rout AK, Strub M-P, Piszczek G, Tjandra N (2014) Structure of transmembrane domain of lysosome-associated membrane protein type 2a (LAMP-2A) reveals key features for substrate specificity in chaperone-mediated autophagy. J Biol Chem 289:35111-35123.

41. Oxenoid K, Chou JJ (2005) The structure of phospholamban pentamer reveals a channellike architecture in membranes. Proc Natl Acad Sci USA 102:10870-10875.

42. Ma C, Polishchuk AL, Ohigashi Y, Stouffer AL, Schön A, Magavern E, Jing X, Lear JD, Freire E, Lamb RA et al. (2009) Identification of the functional core of the influenza A virus A/M2 proton-selective ion channel. Proc Natl Acad Sci USA 106:12283-12288.

43. Li Y, Liew LSY, Li Q, Kang C (2016) Structure of the transmembrane domain of human nicastrin-a component of $\gamma$-secretase. Sci Rep 6:19522.

44. Zheng H, Zhao J, Sheng W, Xie X-Q (2006) A transmembrane helix-bundle from G-protein coupled receptor $\mathrm{CB} 2$ : biosynthesis, purification, and NMR characterization. Biopolymers $83: 46-61$.

45. Chipot C, Dehez F, Schnell JR, Zitzmann N, Pebay-Peyroula E, Catoire LJ, Miroux B, Kunji ERS, Veglia G, Cross TA et al. (2018) Perturbations of native membrane protein structure in alkyl phosphocholine detergents: A critical assessment of NMR and biophysical studies. Chem Rev 118:3559-3607. 


\section{FIGURE LEGENDS}

Figure 1. A flowchart of non-deuterated DPC indirectly replaced by deuterated DPC- $d_{38}$. Binding of DPC detergent favors and maintains Vpx conformation and prevents aggregation. The interaction of Vpx with DPC molecules was disrupted by acetonitrile and DPC was then present in free form. The original conformation of the protein was conserved under the hydrophobic environment. Prior to lyophilization, the deuterated DPC- $d_{38}$ was supplied to maintain and protect Vpx protein. Finally, the lyophilized sample was dissolved in acetate buffer for NMR studies.

Figure 2. Efficiency of DPC removal followed by NMR. All spectra were recorded in acetate buffer $\mathrm{A}$ at $323 \mathrm{~K}$ and $\mathrm{pH}$ 4.0. (A) 1D proton spectrum of DPC (30 mM). The seven proton resonances (labelled I to VII) are from DPC. (B) $0.3 \mathrm{mM}$ Vpx proton spectrum with 100 equivalents protonated DPC. (C) $0.3 \mathrm{mM}$ Vpx with 100 equivalents DPC- $d_{38}$ after lyophilization and resuspension according to the protocol described here. All DPC proton signals were suppressed allowing proper observation on the protein spectrum.

Figure 3. ${ }^{1} \mathrm{H}-{ }^{15} \mathrm{~N}$ SOFAST-HMQC spectrum of $0.3 \mathrm{mM}{ }^{13} \mathrm{C},{ }^{15} \mathrm{~N}$-labeled $\mathrm{Vpx}$ in $30 \%$ acetonitrile recorded at $323 \mathrm{~K}$ and $600 \mathrm{MHz}$.

Figure 4. DPC as a freeze-drying protective agent. (A) Vpx solubilized in $30 \%$ acetonitrile and DPC-free buffer. After lyophilization, the protein self-aggregates, and powder is attached on 
the wall of the eppendorf. (B) Deuterated DPC- $d_{38}$ added in a 100: 1 molar ratio to Vpx in acetonitrile, prior to lyophilization. The resulting powder is loose and porous.

Figure 5. Series of ${ }^{1} \mathrm{H}-{ }^{15} \mathrm{~N}$ SOFAST-HMQC spectra of $0.3 \mathrm{mM}{ }^{13} \mathrm{C},{ }^{15} \mathrm{~N}$-labeled Vpx recorded in acetate buffer $\mathrm{A}$ at $323 \mathrm{~K}$ in the presence of DPC- $d_{38}$ for DPC- $d_{38}$-to-DSP molar ratios of 100:1 (A), 200:1 (B), 300:1 (B), 400:1 (D), and 500:1 (E). Vpx structure was stabilized as DPC- $d_{38}$ quantity increased. (F) Superposition of spectra recorded for 300:1 and 400:1 ratio. A molar ratio of 400:1 only induces slight changes compared to 300:1. 
Figure 1
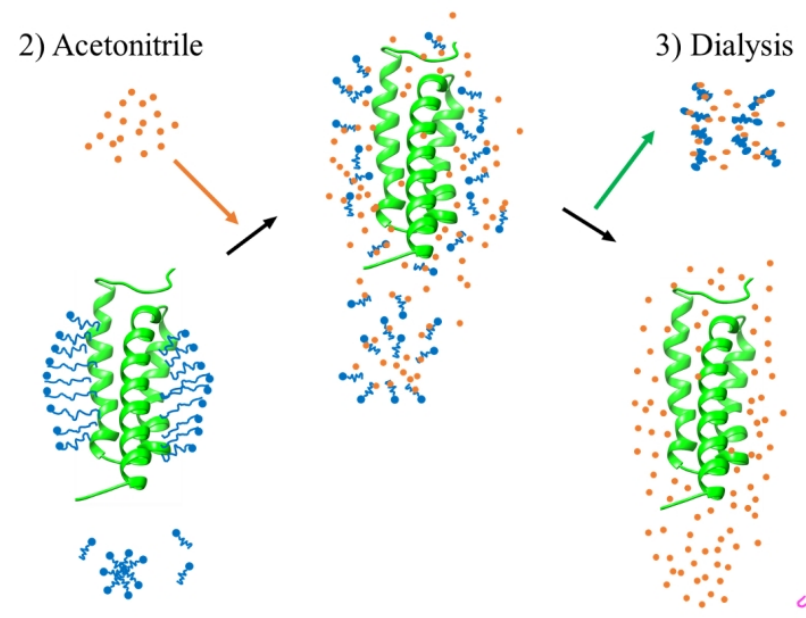

1) $\mathrm{Vpx}$ in nondeuterated DPC

7) Vpx in DPC- $d_{38}$

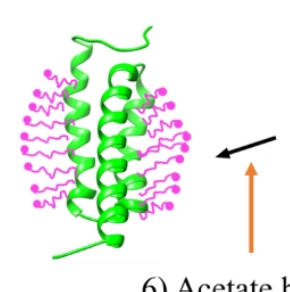

6) Acetate buffer

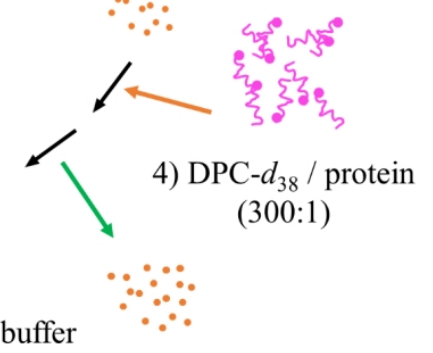

5) Lyophilization

Figure 1. A flowchart of non-deuterated DPC indirectly replaced by deuterated DPC-d38. Binding of DPC detergent favors and maintains Vpx conformation and prevents aggregation. The interaction of Vpx with DPC molecules was disrupted by acetonitrile and DPC was then present in free form. The original conformation of the protein was conserved under the hydrophobic environment. Prior to lyophilization, the deuterated DPCd38 was supplied to maintain and protect Vpx protein. Finally, the lyophilized sample was dissolved in acetate buffer for NMR studies. 
Figure 2

A $\mathrm{pH} 4$ sodium acetate $10 \mathrm{mM}, \mathrm{NaCl} 50 \mathrm{mM}, \mathrm{BME} 5$ $\mathrm{mM}, \mathrm{DPC} 30 \mathrm{mM}, \mathrm{ZnCl}_{2} 2 \mathrm{mM}, 323 \mathrm{~K}$
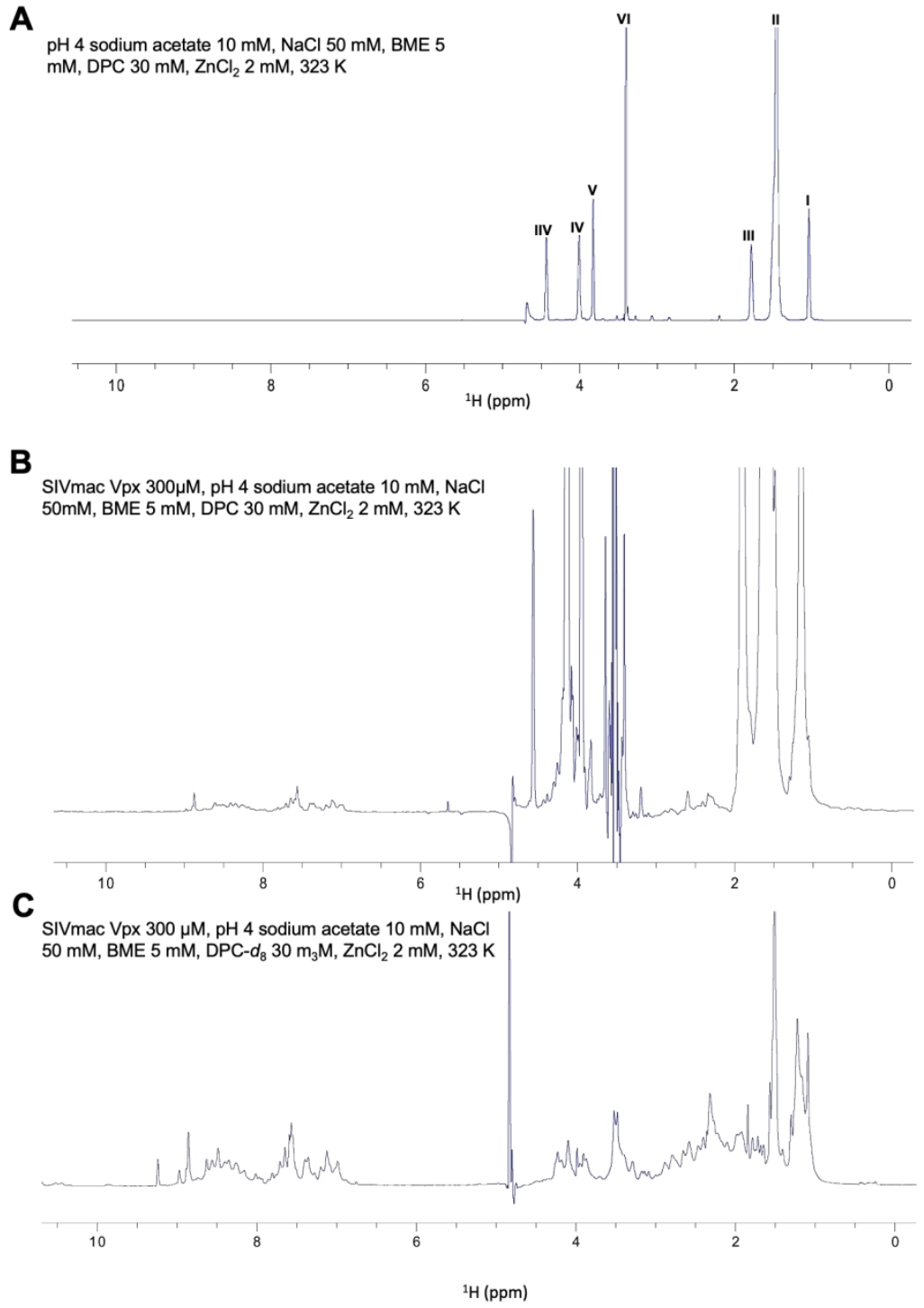

Figure 2. Efficiency of DPC removal followed by NMR. All spectra were recorded in acetate buffer $\mathrm{A}$ at $323 \mathrm{~K}$ and $\mathrm{pH}$ 4.0. (A) 1D proton spectrum of DPC (30 mM). The seven proton resonances (labelled I to VII) are from DPC. (B) $0.3 \mathrm{mM}$ Vpx proton spectrum with 100 equivalents protonated DPC. (C) $0.3 \mathrm{mM} \mathrm{Vpx} \mathrm{with} 100$ equivalents DPC-d38 after lyophilization and resuspension according to the protocol described here. All DPC proton signals were suppressed allowing proper observation on the protein spectrum. 
Figure 3

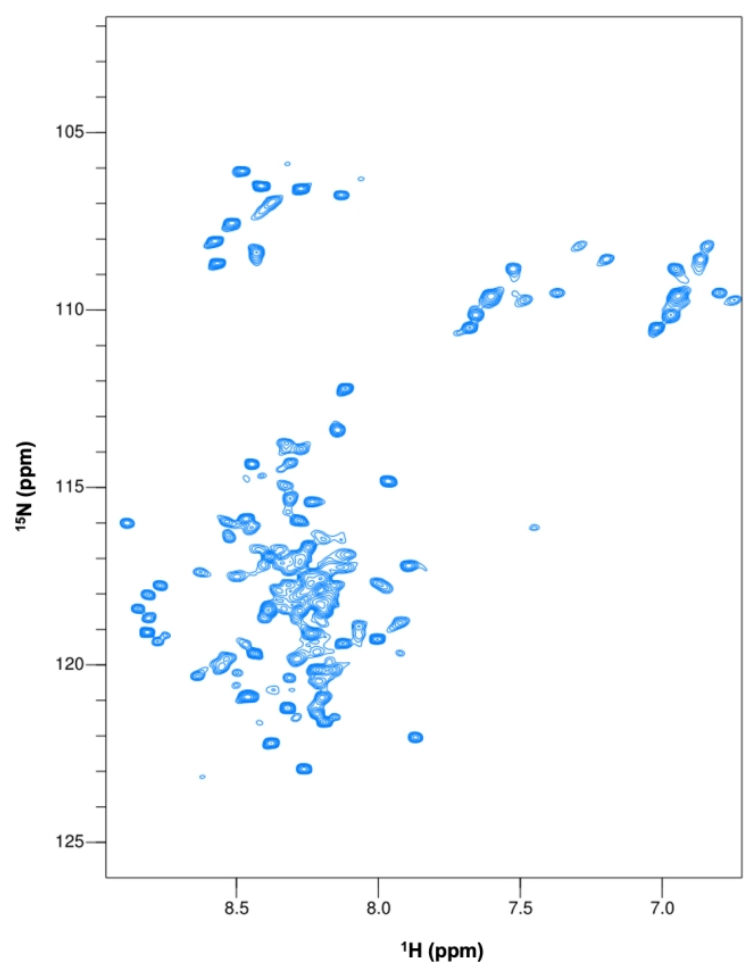

Figure 3. $1 \mathrm{H}-15 \mathrm{~N}$ SOFAST-HMQC spectrum of $0.3 \mathrm{mM} 13 \mathrm{C}, 15 \mathrm{~N}$-labeled $\mathrm{Vpx}$ in $30 \%$ acetonitrile recorded at $323 \mathrm{~K}$ and $600 \mathrm{MHz}$. 
Figure 4

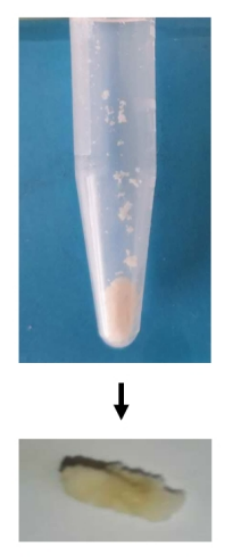

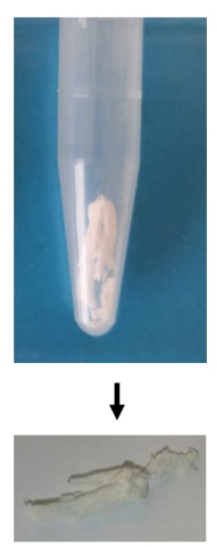

Figure 4. DPC as a freeze-drying protective agent. (A) Vpx solubilized in $30 \%$ acetonitrile and DPC-free buffer. After lyophilization, the protein self-aggregates, and powder is attached on the wall of the eppendorf.

(B) Deuterated DPC-d38 added in a 100: 1 molar ratio to Vpx in acetonitrile, prior to lyophilization. The resulting powder is loose and porous. 


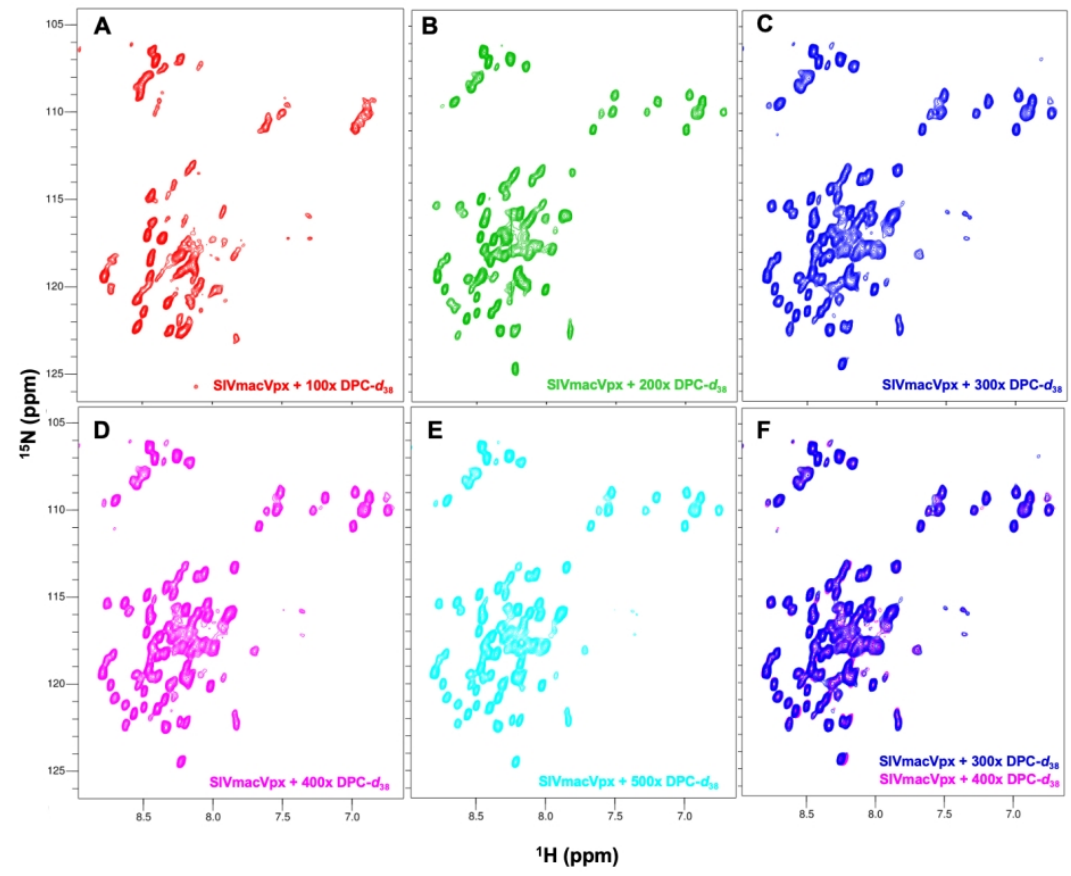

Figure 5. Series of $1 \mathrm{H}-15 \mathrm{~N}$ SOFAST-HMQC spectra of $0.3 \mathrm{mM} 13 \mathrm{C}, 15 \mathrm{~N}$-labeled Vpx recorded in acetate buffer $A$ at $323 \mathrm{~K}$ in the presence of DPC-d38 for DPC-d38-to-DSP molar ratios of 100:1 (A), $200: 1$ (B), 300:1 (B), 400:1 (D), and 500:1 (E). Vpx structure was stabilized as DPC-d38 quantity increased. (F) Superposition of spectra recorded for 300:1 and 400:1 ratio. A molar ratio of 400:1 only induces slight changes compared to $300: 1$. 
Figure S1

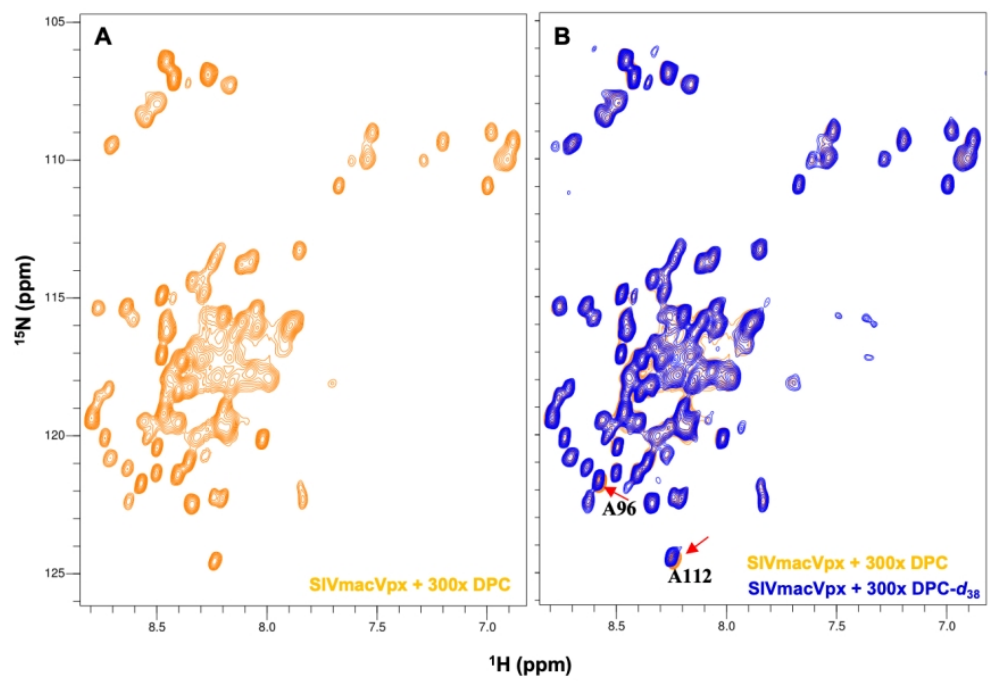

Figure S1. $1 \mathrm{H}-15 \mathrm{~N}$ SOFAST-HMQC spectra of $0.3 \mathrm{mM} \mathrm{13C}, 15 \mathrm{~N}$-labeled Vpx recorded in acetate buffer $\mathrm{A}$ at $323 \mathrm{~K}$ at pH 4.0, in the presence of DPC (A) and its superposition with the spectra recorded in the presence of DPC-d38 (B). Two residues A96 and A112 (red arrows) located the C-terminal have slight change in chemical shift probably resulting from indirect effects of the flexibility of the C-terminus. 